Case Report

\title{
Loxapine and Cyproheptadine Combined Limit Clozapine Rebound Psychosis and May Also Predict Clozapine Response
}

\author{
Lila Aboueid ${ }^{1}$ and Richard H. McCarthy ${ }^{2}$ \\ ${ }^{1}$ SUNY Downstate Medical Center, Department of Psychiatry, 450 Clarkson Avenue, Brooklyn, NY 11203, USA \\ ${ }^{2}$ Kingsboro Psychiatric Center, 681 Clarkson Avenue, Brooklyn, NY 11203, USA \\ Correspondence should be addressed to Lila Aboueid; lila.aboueid@gmail.com
}

Received 7 May 2016; Accepted 8 June 2016

Academic Editor: Toshiya Inada

Copyright (C) 2016 L. Aboueid and R. H. McCarthy. This is an open access article distributed under the Creative Commons Attribution License, which permits unrestricted use, distribution, and reproduction in any medium, provided the original work is properly cited.

\begin{abstract}
Clozapine has been consistently shown to be superior to other antipsychotics in the treatment of psychosis. However, clozapine usage has been limited due to required routine blood monitoring and the potential for life threatening side effects. We report a case of a 66-year-old female patient, who developed clozapine-induced agranulocytosis after 10 weeks of clozapine treatment and was subsequently successfully treated with a combination of loxapine and cyproheptadine. The combination is thought to mimic the pharmacological profile of clozapine, rendering it as a possible alternative to traditional clozapine treatment.
\end{abstract}

\section{Introduction}

Clozapine, the only FDA approved antipsychotic used in treatment refractory schizophrenia and suicidality, has consistently been shown to be more effective than any other antipsychotic medication. However, clozapine-induced agranulocytosis limits clozapine's use, and when it occurs, clozapine must be stopped and cannot be restarted. This not only results in the loss of incremental benefits that clozapine afforded, but also may lead to particularly severe, difficult to treat rebound psychosis. Cyproheptadine has been shown to limit this rebound. Cyproheptadine, an atypical serotonin 2 antagonist, mimics some of clozapine's actions [1]. In addition to softening clozapine discontinuation symptoms, cyproheptadine, like clozapine, decreases negative symptoms [2], increases appetite and weight gain [3], and improves extrapyramidal symptoms (EPS) and motor symptoms [4].

Additionally, loxapine, a dibenzoxazepine tricyclic antipsychotic, with a chemical structure very similar to clozapine, is proposed to be mediated through high-affinity antagonism of postsynaptic dopamine D2 receptors and serotonin 5-HT2A receptors. Loxapine has not only been shown to be effective in the treatment of schizophrenia, but has recently been approved for the treatment of mild-moderate agitation in adults with schizophrenia or bipolar disorder available for inhalational administration [5].

There has been considerable speculation about clozapine's exact mechanism of action, but it remains unknown. Using PET data Kapur and Zipursky reasoned that a loxapine and cyproheptadine combination could have a 5HT-2A/D2 ratio, D4, antihistamine, and antimuscarinic receptor blockade profile similar to clozapine [1]. Receptor blockade studies by others also support this [6]. The combination of cyproheptadine and loxapine may mimic clozapine's mechanism of action and, thus, is postulated as an alternative to traditional clozapine usage.

\section{Case Presentation}

This is the case of a 66-year-old Caucasian female, with a long history of treatment of refractory schizophrenia. In spite of multiple antipsychotic medication trials and current medication regimen (lithium $450 \mathrm{mg}$ daily, quetiapine $300 \mathrm{mg}$ daily, and gabapentin $200 \mathrm{mg}$ daily), the patient's paranoid delusions had not abated. Her daily life was increasingly impaired by her delusions and she was referred for a clozapine trial (started 5/12/14). Clozapine was titrated to a maximum daily dose of $300 \mathrm{mg}$ daily, lithium was continued at $450 \mathrm{mg}$ 
TABLE 1

\begin{tabular}{|c|c|c|c|c|c|c|c|c|c|}
\hline Date & WBC & ANC & $\begin{array}{c}\text { Clozapine } \\
\text { (mg/day) }\end{array}$ & $\begin{array}{l}\text { Lithium } \\
\text { (mg/day) }\end{array}$ & $\begin{array}{c}\text { Quetiapine } \\
\text { (mg/day) }\end{array}$ & $\begin{array}{c}\text { Gabapentin } \\
\text { (mg/day) }\end{array}$ & $\begin{array}{c}\text { Clonazepam } \\
\text { (mg/day) }\end{array}$ & $\begin{array}{c}\text { Cyproheptadine } \\
\text { (mg/day) }\end{array}$ & $\begin{array}{l}\text { Loxapine } \\
\text { (mg/day) }\end{array}$ \\
\hline $05 / 06 / 14$ & 4.8 & 2.8 & & 450 & 300 & 200 & 0.5 qid prn & & \\
\hline $05 / 12 / 14$ & 7.3 & 4.7 & 12.5 & 450 & 300 & 200 & 0.5 qid prn & & \\
\hline $05 / 12 / 14$ & 7.3 & 4.7 & 37.5 & 450 & 300 & 200 & 0.5 qid prn & & \\
\hline $05 / 17 / 14$ & 6.4 & 4 & 100 & 450 & 300 & 200 & 0.5 bid prn & & \\
\hline $05 / 27 / 14$ & 11.1 & 8.8 & 50 & 450 & 300 & 200 & 0.5 bid prn & & \\
\hline $06 / 02 / 14$ & 14.7 & 12.8 & 50 & 450 & 300 & 200 & 0.5 daily prn & & \\
\hline 06/10/14 & 10.8 & 7.5 & 100 & 450 & 300 & 200 & 0.5 daily prn & & \\
\hline $06 / 16 / 14$ & 12.8 & 10.2 & 150 & 450 & 300 & 100 & 0.5 daily prn & & \\
\hline $06 / 24 / 14$ & 8.4 & 5.8 & 150 & 450 & 250 & 0 & 0 & & \\
\hline $06 / 28 / 14$ & 7.4 & 5.5 & 150 & 450 & 200 & & & & \\
\hline 07/05/14 & 10.5 & 8.5 & 150 & 450 & 50 & & & & \\
\hline $07 / 12 / 14$ & 6.8 & 4.8 & 125 & 450 & 50 & & & & \\
\hline 07/19/14 & 6.2 & 4.6 & 150 & 450 & 0 & & & & \\
\hline $07 / 22 / 14$ & 6.2 & 4.5 & 200 & 450 & & & & & \\
\hline $07 / 28 / 14$ & 4.5 & 2.7 & 300 & 450 & & & & & \\
\hline $08 / 01 / 14$ & 1.4 & 0.1 & & 450 & & & & 16 & \\
\hline $08 / 02 / 14$ & 2.4 & 0.029 & & 450 & & & 0.5 bid & 16 & \\
\hline 08/03/14 & 1.4 & 0.1 & & 450 & & & $0.5 \mathrm{bid}$ & 16 & \\
\hline $08 / 04 / 14$ & 1.2 & 0.03 & & 450 & & & 0.5 bid & 16 & \\
\hline $08 / 04 / 14$ & 1.2 & 0.03 & & 450 & & & 0.5 bid & 16 & \\
\hline $08 / 06 / 14$ & 1 & 0.3 & & 0 & & & $0.5 \mathrm{bid}$ & 16 & \\
\hline 08/08/14 & 1.9 & 0.021 & & & & & $0.5 \mathrm{bid}$ & 16 & \\
\hline 08/11/14 & 10.4 & 1.72 & & & & & $0.5 \mathrm{bid}$ & 16 & 10 \\
\hline $08 / 20 / 14$ & 7.7 & 5.8 & & & & & 0.5 bid & 16 & 10 \\
\hline $09 / 12 / 14$ & 10.4 & 7.6 & & & & & 0.5 bid & 16 & 10 \\
\hline
\end{tabular}

daily, and quetiapine and gabapentin were titrated off and discontinued (see Table 1). The patient had a rapid and significant decrease in her delusions, documented early in the clozapine trial, which continued to abate with subsequent dose increases.

Initially, hypotension limited dose increases, but at ten weeks she had a precipitous drop in her white blood cells (WBC) and absolute neutrophil count (ANC) (Figure 1) that proceeded to full blown agranulocytosis over a three-day period. Filgrastim treatment was begun; clonazepam was used to contain anxiety and the patient was started on cyproheptadine $4 \mathrm{mg}$ TID to prevent clozapine discontinuation rebound psychosis. When the patient's hematological indices returned to normal, the patient was begun on loxapine $10 \mathrm{mg}$ daily to address her newly returned paranoid delusions. Over the next three weeks, the patient's delusions continued to decrease to levels lower than they had been on clozapine. At this time, about two years after clozapine discontinuation, the delusions are only minimally present and do not result in any interference in the patient's daily life.

\section{Discussion}

Clozapine is well known for its efficacy in patients with treatment of resistant schizophrenia. Although clozapine

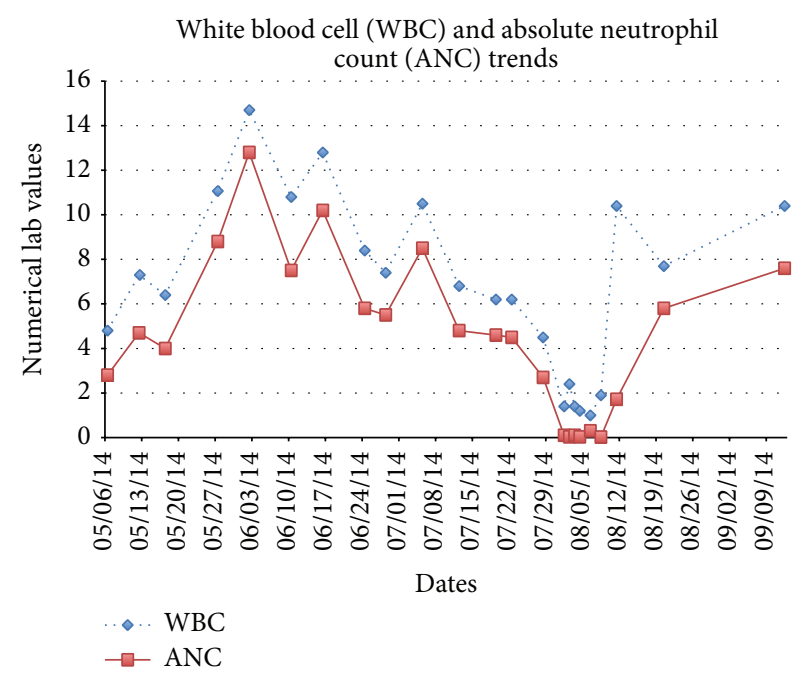

Figure 1

may be clinically effective, the treatment may be stopped abruptly due to patient nonadherence, side effects (i.e., neutropenia/agranulocytosis), and/or medical complications (i.e., stroke, seizure, pulmonary embolism, etc.). Possible 
consequences of abrupt clozapine discontinuation include the rapid onset of an unusually severe psychotic relapse that is largely unresponsive to other treatments [7], the psychotic relapse following clozapine's rapid discontinuation can be prolonged [8], and/or the patient may not respond to clozapine when it is reintroduced in the future [9]. In some cases, clozapine discontinuation may result in delirium [10], severe anxiety, altered levels of consciousness, mental status changes, insomnia [11], somatic complaints including nausea, vomiting, diaphoresis, akathisia, motor restlessness, and dyskinetic movements, and excited catatonia and/or neuroleptic malignant syndrome (NMS) [12] that may cloud the clinical picture.

Clozapine, along with other atypical psychotics, fundamentally differs from typical antipsychotics in that they block a high number of serotonin receptors and lower number of D2 receptors. Given this pharmacological profile, it is reasonable to assume other agents with similar properties may be combined in effort to treat psychosis. However, the dose of the antipsychotic should be low enough to provide a low level of D2 blockage (less than $80 \%$ occupancy) to retain the dopamine and serotonin blockage. Based on previous studies, $15 \mathrm{mg}$ /day of loxapine would result in lower than $80 \%$ receptor occupancy (typical dosage used is $25-100 \mathrm{mg} / \mathrm{day}$, where D2 occupancy is greater than $80 \%)$. Cyproheptadine has been known to block $85-95 \%$ of serotonin 2 receptors in humans with doses of $12-18 \mathrm{mg} /$ day. Thus, the combination of the two medications has been formulated to yield a similar pharmacological profile seen with clozapine, as well as other atypical antipsychotics [1].

The combination of loxapine and cyproheptadine mimics some of clozapine's action. In cases where a clozapine responder must discontinue the medication, there may be an alternative to clozapine's use. In addition, patients reluctant to take clozapine may be offered this combination to determine if clozapine or this combination may benefit them. Further assessment for the use of loxapine and cyproheptadine is indicated.

\section{Consent}

Consent was obtained from the patient.

\section{Competing Interests}

The authors declare that there are no competing interests regarding the publication of this paper.

\section{References}

[1] S. Kapur and R. B. Zipursky, "Do loxapine plus cyproheptadine make an atypical antipsychoticPET analysis of their dopamine D2 and serotonin2 receptor occupancy," Archives of General Psychiatry, vol. 53, no. 7, pp. 666-667, 1998.

[2] S. Akhondzadeh, M. R. Mohammadi, H. Amini-Nooshabadi, and R. Davari-Ashtiani, "Cyproheptadine in treatment of chronic schizophrenia: a double-blind, placebo-controlled study," Journal of Clinical Pharmacy and Therapeutics, vol. 24, no. 1, pp. 49-52, 1999.
[3] C. D. Summerbell, M. Youle, V. McDonald, J. Catalan, and B. G. Gazzard, "Megestrol acetate vs cyproheptadine in the treatment of weight loss associated with HIV infection," International Journal of STD and AIDS, vol. 3, no. 4, pp. 278-280, 1992.

[4] N. M. Bacher, H. A. Lewis, and P. B. Field, "Cyproheptadine in movement disorders," The American Journal of Psychiatry, vol. 146, no. 4, pp. 557-558, 1989.

[5] L. Citrome, "Aerosolised antipsychotic assuages agitation: inhaled loxapine for agitation associated with schizophrenia or bipolar disorder," International Journal of Clinical Practice, vol. 65, no. 3, pp. 330-340, 2011.

[6] B. L. Roth, D. J. Sheffer, and W. K. Kroeze, "Magic shotguns versus magic bullets: selectively non-selective drugs for mood disorders and schizophrenia," Nature Reviews Drug Discovery, vol. 3, no. 4, pp. 353-359, 2004.

[7] R. L. Borison, B. I. Diamond, D. Sinha, R. P. Gupta, and P. A. Ajiboye, "Clozapine withdrawal rebound psychosis," Psychopharmacology Bulletin, vol. 24, no. 2, pp. 260-263, 1988.

[8] M. A. Parsa, Y. H. Al-Lahham, L. F. Ramirez, and H. Y. Meltzer, "Prolonged psychotic relapse after abrupt clozapine withdrawal," Journal of Clinical Psychopharmacology, vol. 13, no. 2, pp. 154-155, 1993.

[9] B. L. Szarek, J. W. Goethe, and P. G. Pentz, "Unsuccessful reexposure to clozapine," Journal of Clinical Psychopharmacology, vol. 17, no. 1, pp. 71-73, 1997.

[10] J. K. Stanilla, J. de Leon, and G. M. Simpson, "Clozapine withdrawal resulting in delirium with psychosis: a report of three cases," Journal of Clinical Psychiatry, vol. 58, no. 6, pp. 252$255,1997$.

[11] J. Staedt, G. Stoppe, G. Hajak, and E. Rüther, "Rebound insomnia after abrupt clozapine withdrawal," European Archives of Psychiatry and Clinical Neuroscience, vol. 246, no. 2, pp. 7982, 1996.

[12] J. W. Y. Lee and S. Robertson, "Clozapine withdrawal catatonia and neuroleptic malignant syndrome: a case report," Annals of Clinical Psychiatry, vol. 9, no. 3, pp. 165-169, 1997. 


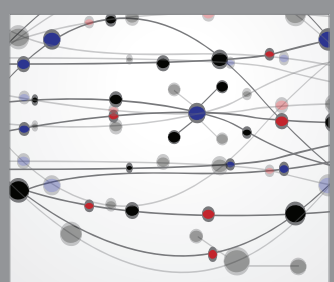

The Scientific World Journal
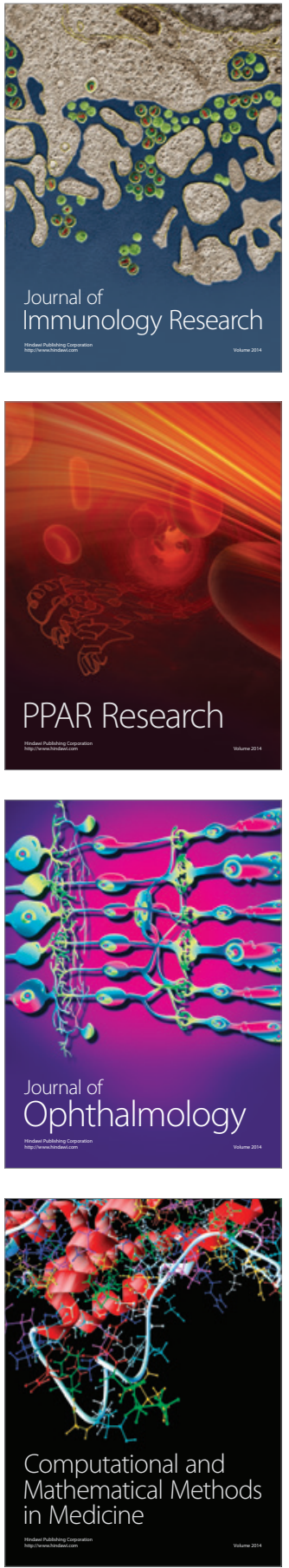

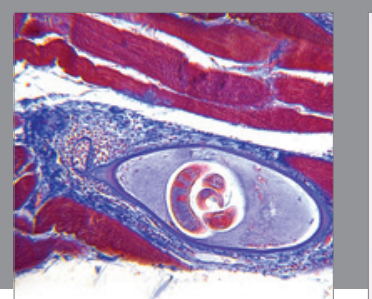

Gastroenterology Research and Practice

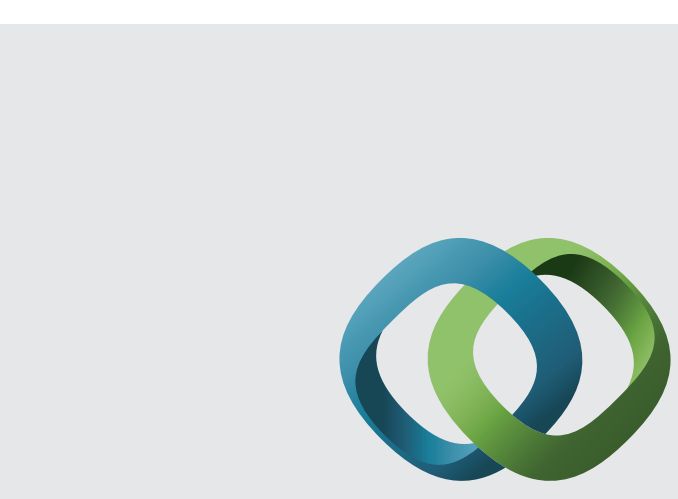

\section{Hindawi}

Submit your manuscripts at

http://www.hindawi.com
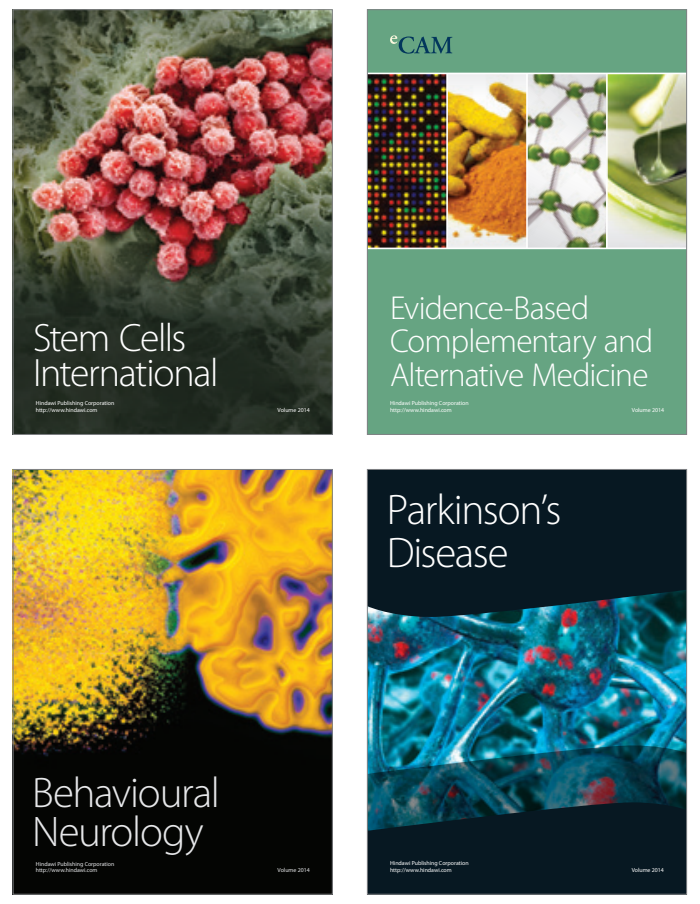
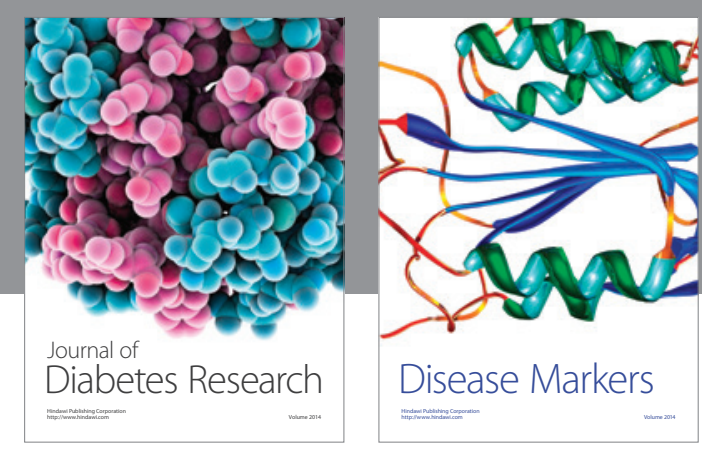

Disease Markers
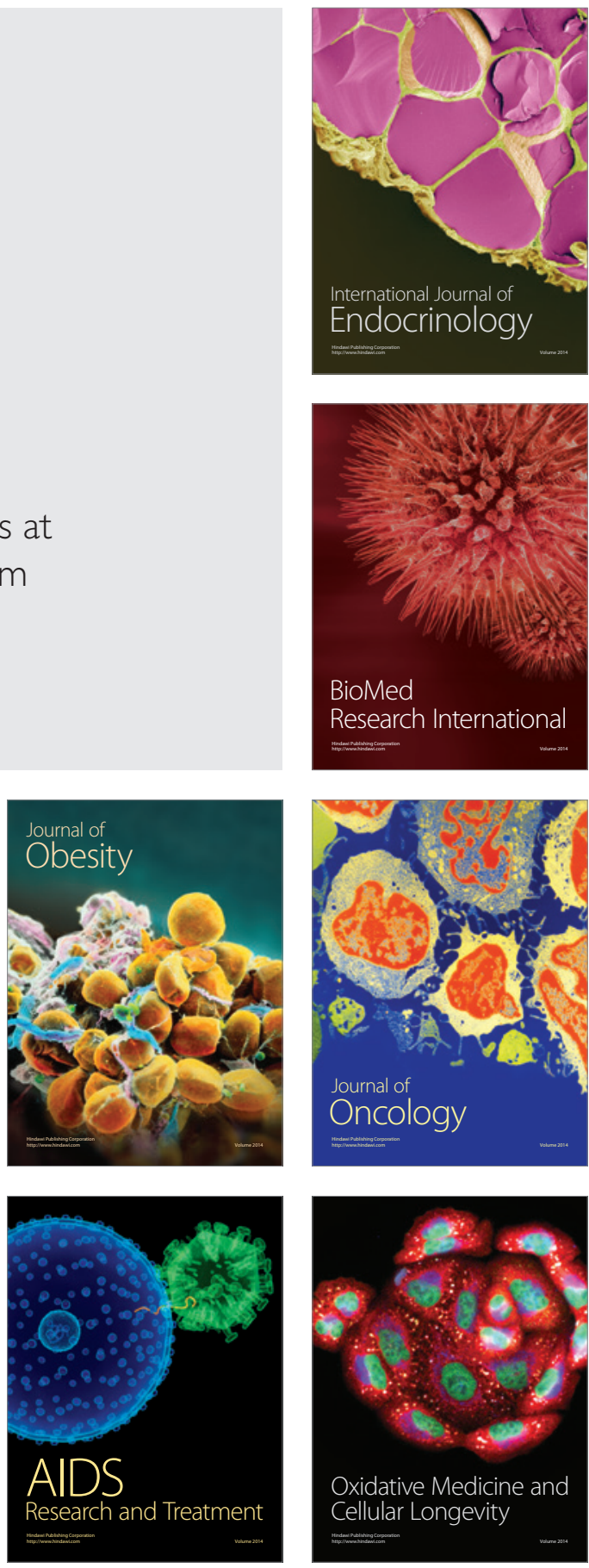